\title{
The use of bacterial luciferase genes as reporter genes in Lactococcus: regulation of the Lactococcus lactis subsp. lactis lactose genes
}

\author{
Tracy J. Eaton, Claire A. Shearman and Michael J. Gasson* \\ AFRC Institute of Food Research, Norwich Research Park, Colney, Norwich NR4 7UA, UK
}

(Received 16 November 1992; revised 15 February 1993; accepted 5 March 1993)

\begin{abstract}
Lactose metabolism is an important industrial trait in dairy lactococci. In Lactococcus lactis, lactose is taken up via the phosphoenolpyruvate-dependent phosphotransferase system (PEP-PTS) and is subsequently metabolized via the glycolytic and tagatose 6-phosphate pathways. Genes for the lactose-specific PEP-PTS proteins, phospho$\beta$-galactosidase and tagatose 6-phosphate pathway enzymes are encoded by a single $8 \mathrm{~kb}$ operon, lacABCDFEGX, and there is a divergently transcribed $l a c R$ repressor gene. Transcriptional fusions of both the lac operon promoter and the lacR promoter to the luxAB genes of Vibrio fischeri were used to investigate the regulation of expression of both promoters. In vivo bioluminescence assays demonstrated that lacR negatively regulates the lac operon and also autoregulates itself. Induction of transcription occurred for both promoters during growth on lactose: sevenfold for $l a c R$ and fivefold for the $l a c$ operon. The lacR promoter was demonstrated to be a particularly strong promoter, being approximately four times more efficient than the lac operon promoter. Both promoters provide good potential for the inducible expression of foreign proteins in Lactococcus.
\end{abstract}

\section{Introduction}

Lactic acid bacteria are of major economic and nutritional importance, being used extensively in both the production and preservation of a wide variety of fermented food products. Genetic studies of these bacteria are aimed at the characterization of industrially relevant traits and the application of molecular techniques for strain improvement. The majority of industrially important traits are plasmid encoded and this has facilitated rapid analysis of genes for key catabolic pathways. The genetic determinants of several enzymes involved in protein degradation (Kok et al., 1988; Vos et al., 1989), citrate utilization (David et al., 1990; Verhue \& Tjan, 1991) and sugar metabolism (De Vos \& Gasson, 1989; De Vos et al., 1990; Van Rooijen et al., 1991) have been cloned and characterized. An important aspect of genetic technology is the analysis of gene expression signals and the characterization of regulatory elements. Strong controllable promoters are an essential requirement both for the efficient expression of heterologous genes and for the optimum exploitation of homologous

\footnotetext{
*Author for correspondence. Tel. 0603 56122; fax 0603507723.

Abbreviation: PEP-PTS, phosphoenolpyruvate-dependent phosphotransferase system.
}

genes. In many cases the analysis of promoters depends on their fusion to reporter genes which can then be assayed and used to monitor levels of transcription.

Bacterial luciferase genes have been used widely as in vivo reporters of gene expression in Gram-negative bacteria and there are a growing number of examples of lux as a monitor in Gram-positive species (Schauer et al., 1988; Guijarro et al., 1988; Carmi et al., 1987; Ahmad \& Stewart, 1991; Sohaskey et al., 1992). Light emission has several advantages over alternative systems, providing rapid assays of superior sensitivity without the need for cell disruption and resulting in real-time expression data (for reviews, see Meighen, 1988, 1991; Stewart \& Williams, 1992). This study describes the use of the lux genes of Vibrio fischeri as reporter genes to investigate the regulation of expression from the lactose operon promoters of Lactococcus lactis subsp. lactis.

In $L$. lactis lactose is taken up via the phosphoenolpyruvate-dependent phosphotransferase system (PEP-PTS). Lactose becomes phosphorylated during entry into the cell and the lactose 6-phosphate is cleaved by phospho- $\beta$-galactosidase to yield glucose and galactose 6-phosphate, which are subsequently metabolized via the glycolytic and tagatose 6-phosphate pathways respectively (Blisset \& Anderson, 1973). A single $8 \mathrm{~kb}$ operon, lacABCDFEGX (hereafter the lac operon), encodes the genes for the lactose-specific PEP- 
PTS enzymes, phospho- $\beta$-galactosidase and the tagatose 6-phosphate pathway (De Vos et al., 1990; Van Rooijen et al., 1991). Recent work has provided more information about the regulatory regions associated with the lactose operon and its possible mechanisms of control. However, a complete molecular model of $L$. lactis lac operon regulation has yet to be determined. A repressor protein, produced by the divergently transcribed lac $R$ gene, is known to regulate expression of the lac operon at the transcriptional level (Van Rooijen \& De Vos, 1990; De Vos et al., 1990). During growth on glucose, expression of the lac operon is repressed at least fivefold and recent work (Van Rooijen et al., 1992) has indicated that the DNA sequences flanking the lac promoter are involved in transcriptional activity, regulation and possibly stability of the transcripts produced. Transcriptional fusion of the promoters for both the lac operon and lacR to the lux $A B$ reporter genes of $V$. fischeri was used in this study to further characterize lactose gene expression. As well as demonstrating the value of luciferase as a reporter system in lactococci, the potential of the lactose promoter for control and high-level expression of heterologous genes is established. This study also demonstrates that the lactose operon provides a regulatory system, which can be exploited to provide a series of promoters producing different levels of inducible gene expression.

\section{Methods}

Bacterial strains and media. Escherichia coli MC1022 (Casabadan \& Cohen, 1980) was used in the plasmid cloning experiments. L. lactis strains used were the plasmid-free, lactose negative strain MG1363 (Gasson, 1983) and MG5267, which contains chromosomally integrated lactose genes (S. R. Swindell \& M. J. Gasson, unpublished). M17 medium was used for growth of L. lactis at $30^{\circ} \mathrm{C}$. The carbon source was either $0.5 \%$ (w/v) lactose (LM17) (Terzaghi \& Sandine, 1975 ) or $0.5 \%$ glucose (GM17) or a mixture of both sugars, each at $0.5 \%$ (GLM17). L broth (Lennox, 1955) was used for growth of $E$. coli at $37^{\circ} \mathrm{C}$. Where appropriate, media were supplemented with ampicillin at $100 \mu \mathrm{g} \mathrm{ml}^{-1}$ for $E$. coli, chloramphenicol at $15 \mu \mathrm{g} \mathrm{ml}^{-1}$ and $5 \mu \mathrm{g} \mathrm{ml}^{-1}$, and erythromycin at $500 \mu \mathrm{g} \mathrm{ml}^{-1}$ and $10 \mu \mathrm{g} \mathrm{ml}^{-1}$, for $E$. coli and $L$. lactis respectively.

Plasmids. Plasmid vector pUC18 (Yanisch-Perron et al., 1985) and promoter-probe plasmid pSB292 (Park et al., 1992) were used in the cloning experiments. pSB292 contains translational stop codons in all three reading frames and a multiple cloning site preceding the $l u x A B$ genes, which have their own Shine-Dalgarno sequences (Shine \& Dalgarno, 1974). The lactose plasmid pLP712 (Gasson, 1983) was used as template DNA for PCR amplification of the lactose promoter region.

Molecular cloning, reagents and enzymes. Plasmid DNA was isolated from $E$. coli by the alkaline lysis method (Birnboim \& Doly, 1979). $L$. lactis plasmid DNA was extracted by the same method except that mutanolysin was added at the lysozyme treatment step ( 300 units $\mathrm{ml}^{-1}$ ) and samples were incubated at $37^{\circ} \mathrm{C}$ for $15 \mathrm{~min}$. All in vitro DNA manipulations and $E$. coli methods were performed as described by Maniatis et al. (1982). Transformation of L. lactis was achieved by electroporation of glycine-grown cells (Holo \& Nes, 1989). Restriction enzymes, X-gal and IPTG were purchased from Life Technologies and enzymes were used according to the manufacturers' instructions. Taq polymerase was obtained from Promega and nonyl aldehyde from Aldrich.

Luciferase assays. In vivo lux expression was determined at $30^{\circ} \mathrm{C}$ in an assay cuvette containing $1 \mathrm{ml}$ culture and $5 \mu \mathrm{l}$ nonyl aldehyde. The cuvette was inverted sharply twice and light emission detected immediately using a Turner 20e luminometer. Samples were assayed for $10 \mathrm{~s}$ and the average light emission during the integrate period was recorded. Simultaneously the $\mathrm{OD}_{600}$ of identical samples was measured. Time-course analyses were performed in one of two ways: (i) strains were inoculated directly into GM17 or LM17, or (ii) strains were grown initially in GM17, and the samples harvested by centrifugation at 3000 r.p.m. for 4 min and resuspended gently in the appropriate M17 medium (GM17, LM17 or GLM17). Samples (1 ml) were then removed at regular time intervals and assayed for luminescence. Bioluminescence was measured in light units (LU); $1 \mathrm{LU}=1.5 \times 10^{9}$ quanta $^{-1}$, based on calibration against an ATP luciferin/luciferase standard (Sigma).

PCR amplifications. Oligonucleotide primers for PCR were produced using an ABI DNA synthesizer. The primers used were: P1 (5'GGATTCCGACAAACCATACATTAGA-3'), P2 (5'-GGGATCCGTCTAATTATTTAAGAGTAGTCCAAT- $3^{\prime}$ ) and P3 (5'-GGGATCCGAaAtgCtacGtagaAgtagaAaAtA-3'). Primer binding sites are indicated in Fig. 1. All primers incorporated a synthetic BamHI site at their $5^{\prime}$ end. Primers P1 and P3 were used to generate a fragment which contains both the lac operon and lacR promoters and the whole of the lacR gene together with its putative transcription terminator. Primers P2 and P3 were used to create an equivalent fragment which lacked the transcription terminator. PCR was carried out on $40 \mathrm{ng}$ pLP712 DNA in a $50 \mu \mathrm{l}$ volume of PCR mixture $(10 \mathrm{~mm}-$ Tris $/ \mathrm{HCl} \mathrm{pH} \mathrm{8.3,50} \mathrm{mM-KCl,} 2 \mathrm{~mm}-\mathrm{MgCl}_{2}, 0.01 \%$ gelatin, $100 \mathrm{~mm}$ each dNTP and $0.1 \%$ Triton X-100) containing $100 \mathrm{ng}$ of each primer and 0.5 units $T a q$ polymerase. Samples were overlaid with $50 \mu 1$ mineral oil before being subjected to 25 cycles of $2 \mathrm{~min}$ denaturation at $92^{\circ} \mathrm{C}$, 2 min annealing at $61{ }^{\circ} \mathrm{C}$ and 2 min elongation at $72{ }^{\circ} \mathrm{C}$. PCR products were purified using GeneClean as recommended by the manufacturers (Stratech Scientific) and subsequently treated with T4 polymerase and T4 polynucleotide kinase, before use in cloning experiments.

\section{Results}

\section{Transcriptional fusion of lux to the lac promoter}

Details of the construction of plasmids pFI400, pFI402, pFI517, pFI518 and pFI530 are shown in Fig. 1. The PCR fragment generated by primers $\mathrm{P} 1$ and $\mathrm{P} 3$ was obtained as a pUC18 clone and the $1.34 \mathrm{~kb}$ BamHI fragment from this plasmid was cloned into the BamHI site of pSB292 in both orientations to produce pFI400 and $\mathrm{pFI} 402$. Transcription of the $l u x$ genes is initiated from the lac operon promoter in pFI402 and from the lac $R$ promoter in $\mathrm{pFI} 400$. This fragment included a putative terminator sequence downstream of $l a c R$. This terminator sequence was absent in the $1.25 \mathrm{~kb}$ PCR fragment generated by primers $\mathrm{P} 2$ and P3, which was initially cloned into the $S m a I$ site of pUC18. The same region was excised as a $B a m H I$ fragment and cloned into the BamHI site of pSB292, resulting in a transcriptional fusion between the lacR and lux genes in pFI517. In this 

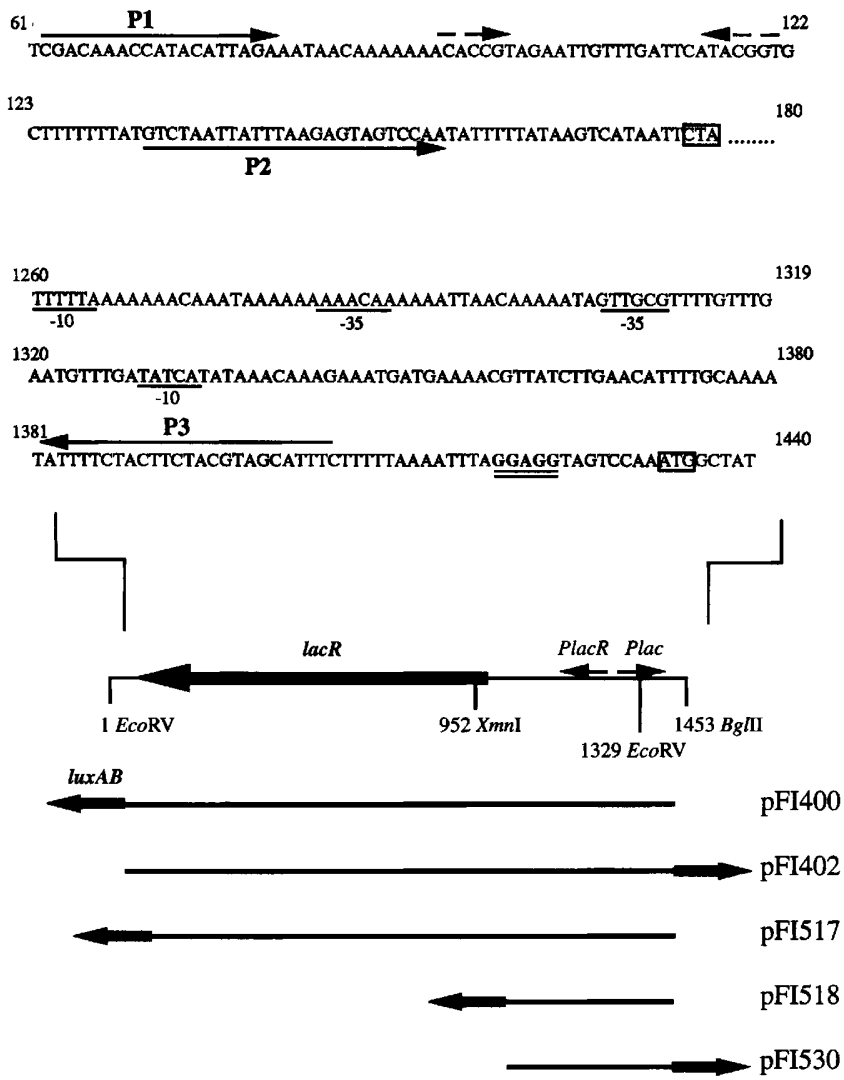

Fig. 1. PCR primers, plasmids and location of promoters for the lac operon and the lacR gene. A restriction map and parts of the nucleotide sequence are shown. Boxed nucleotides indicate translational termination and initiation codons for lacR and lacA respectively. The ribosome-binding site for $l a c A$ is indicated by double underlining. Solid arrows show regions of PCR primer binding sites (P1, P2 and P3); broken arrows show the transcription terminator downstream of lacR. $P l a c R$ and Plac indicate position and direction of the $l a c R$ and $l a c$ operon promoters, respectively.

construct transcription is initiated from the lacR promoter. A PCR fragment comprising solely the promoter region (Fig. 1, bases 967 to 1406) was generated and cloned into pSB292 as described for pFI517 in both orientations, to produce pFI518 and pFI530. Transcription of the lux genes is initiated from the lac operon promoter in pFI530 and from the lacR promoter in pFI518. All plasmids were initially constructed in $E$. coli followed by their transformation into the lactococcal strains MG5267 and MG1363. Although constructs pFI530 and pFI518 appeared stable in E. coli, only pFI530 could be transformed into MG5267. On subsequent subculturing this plasmid was rapidly lost from the cells.

\section{Bioluminescence measurements}

Bioluminescence measurements of untransformed $L$. lactis MG1363 and MG5267 strains and derivatives harbouring pFI400, pFI402, pFI517 or pSB292 were taken at regular intervals during growth at $30^{\circ} \mathrm{C}$. The untransformed strains L. lactis MG1363 and MG5267, and control strains harbouring pSB292, produced only very low levels of luminescence $\left(<50 \mathrm{LU} \mathrm{ml}^{-1}\right)$. Varying levels of luminescence were obtained from MG1363 and MG5267 cells harbouring pFI400, pFI402 and pFI517. Fig. 2(a) shows a representative growth curve for MG5267 and MG1363 harbouring pFI517 during growth in GM17 and LM17. Equivalent strains harbouring pFI400 and pFI402 produced comparable growth curves. Figs $2(b),(c)$ and $(d)$ show plots of bioluminescence vs growth for strains MG5267 and MG1363 harbouring pFI400, pFI402 and pFI517, respectively. Results in GM17 and in LM17 are compared for the MG5267 strains, but only low levels of activity were recorded for MG1363 strains during growth on LM17 and the data are not shown. In order to illustrate the induction of the lac promoters by lactose, transformed MG5267 cells were grown to midexponential phase in GM17 before addition or substitution of $0.5 \%$ lactose as the carbohydrate source (Fig. $3 a, b$ ). Extremely high levels of luminescence were obtained with L. lactis MG5267 (pFI517), making it necessary to dilute samples in order to obtain on-scale luminometer readings. Bioluminescence of established colonies of this strain could be easily visualized within a few seconds with the dark-adapted eye, even in the repressed state during growth on glucose.

MG1363 cells transformed with pFI400 and pFI517 produced similar luminescence levels to the corresponding MG5267 strains when grown in GM17. However, MG1363 transformed with pFI402 produced significantly lower levels of luminescence during growth in GM17 than the corresponding MG5267 strain.

Light emission characteristically reached a peak just before the culture entered stationary phase and thereafter decreased rapidly. The $\mathrm{pH}$ of a growing culture of $L$. lactis drops from pH 6.8 to 5.4 within a few hours. To investigate whether the accumulation of an inhibitory concentration of lactic acid limited the luminescent reaction, the assays were repeated using a fermenter with $\mathrm{pH}$ controlled at 6.8. Comparable values of luminescence were obtained.

\section{Induction of the lac operon and lacR transcription occurs during growth on lactose}

Induction levels in plasmid-carrying MG5267 strains were calculated by dividing the peak luminescence value during growth in LM17 by the value in GM17, at the equivalent optical density. Induction during growth on lactose was approximately fivefold for the lac operon 

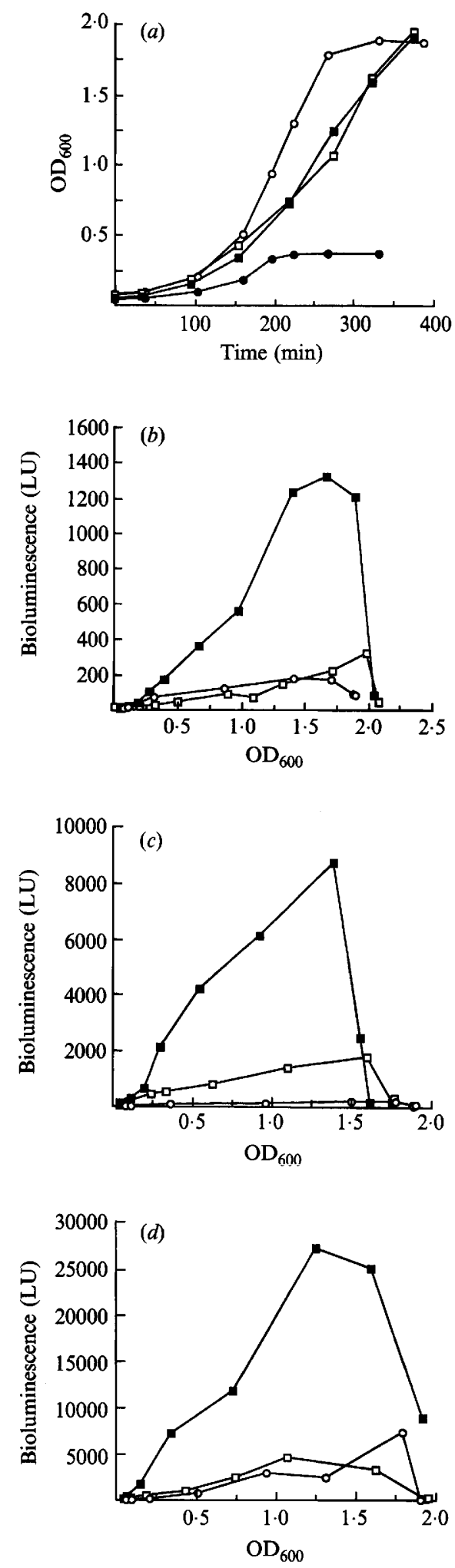

Fig. 2. (a) Growth curve of MG1363(pFI517) during growth on GM17 (O) and LM17 (O) and MG5267(pFI517) during growth on GM17 ( $\square$ ) and LM17 ( $\square)$. (b), (c) and (d) Bioluminescence of growing cultures of MG5267(pFI400), MG5267(pFI402) and MG5267(pFI517), respectively, during growth in GM17 ( $\square$ ) and

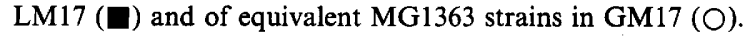
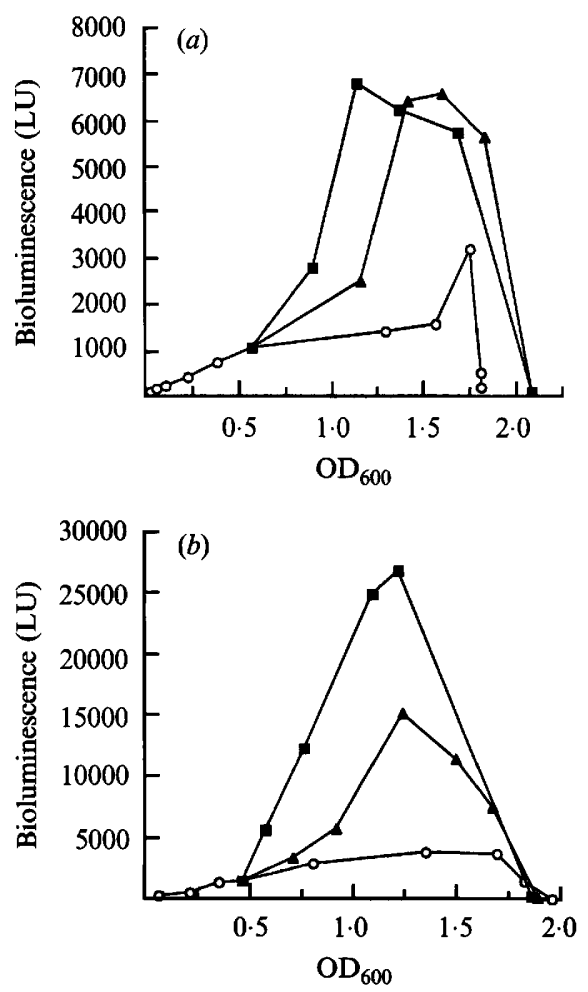

Fig. 3. Induction of bioluminescence in growing cultures of $(a)$ MG5267(pFI402) and (b) MG5267(pFI517) during growth in GM17 (O), after shift to LM17 (ם) and after shift to GLM17 (A).

promoter and sevenfold for the lacR promoter. Comparison of luminescence levels for MG5267 cells harbouring pFI 400 and $\mathrm{pFI} 517$ revealed that the putative transcription terminator downstream of lacR reduced transcription by a factor of 20 . The induction levels of MG5267 strains harbouring pFI402 and pFI517 were significantly lower when lactose was added to GM17 medium rather than being substituted for glucose. Induction was approximately $3 \cdot 5$-fold for the lac operon promoter and $4 \cdot 5$-fold for the lacR promoter.

\section{Discussion}

Previous studies of gene expression in lactococci have relied on the use of chloramphenicol acetyltransferase (CAT) or $\beta$-galactosidase as reporters of gene expression. The homologous phospho- $\beta$-galactosidase gene of $L$. lactis has been proposed as an alternative reporter gene (Simons et al., 1990) and more recently the E. coli $\beta$ glucuronidase (GUS) gene has been successfully used in Lactococcus (W. M. De Vos, personal communication). The lux assay is $10-100$ times more sensitive than the CAT or $\beta$-galactosidase assays. The lux genes have been demonstrated to be suitable monitors of gene expression in vivo and they are particularly useful for the analysis of 
physiologically and environmentally controlled promoters. For the study of temperature-responsive genes and their promoters, however, the luciferases of $V$. harveyi and Xenorhabdus luminescens might be advantageous, being stable at $37^{\circ} \mathrm{C}$ and $42^{\circ} \mathrm{C}$, respectively (Szittner \& Meighen, 1990). $V$. fischeri luciferase is rapidly inactivated at $37^{\circ} \mathrm{C}$ (Friedland \& Hastings, 1967; Sakharov et al., 1988; Ahmad \& Stewart, 1991).

Levels of light emission obtained from Gram-positive bacteria are generally 100 -fold less than those obtained from Gram-negative bacteria (Karp, 1989). Active luciferase depends on the translation of two cotranscribed genes, $\operatorname{lux} A$ and $\operatorname{lu} x B$, and the correct folding of the protein subunits. In Gram-positive bacteria poor expression of luciferase activity could be caused by inefficient translation of the Gram-negative lux genes. Although translational fusion could overcome this for the $\operatorname{lu} x A$ gene it cannot be applied to $\operatorname{lu} x B$ whilst both genes are in an operon. One solution to this problem, which is also relevant to lux gene expression in eukaryotes, is to construct $l u x A B$ fusion genes, thereby eliminating the need for translation initiation in front of the $\operatorname{lux} B$ gene. Several groups have reported the construction of $\operatorname{lux} A B$ fusion genes from $V$. harveyi (Boylan et al., 1989a, b; Kirchner et al., 1989; Olsson et al., 1989; Escher et al., 1989). In E. coli the luciferase activity expressed by these genes was invariably less than that from the equivalent unfused genes. The luciferase produced from fused genes also tended to be more sensitive to high temperature than enzyme consisting of separate subunits. However, recent work in Bacillus subtilis has shown that a $V$. harveyi $\operatorname{lux} A B$ gene fusion expressed from a strong Bacillus promoter with translational coupling produced an equivalent amount of light to one of the most luminescent constructs of $E$. coli (Jacobs et al., 1991). In this case the equivalent luciferase expressed from unfused $\operatorname{lu} x A B$ genes produced dramatically reduced light yields in $B$. subtilis. It is therefore possible that a $\operatorname{lu} x A B$ gene fusion will facilitate the optimization of the luminescent reaction in lactococci.

Light emission in Lactococcus expressing $\operatorname{lux} A B$ reached a peak in late exponential phase and rapidly decreased as cells entered stationary phase. A number of factors may influence the luminescent reaction. On entering stationary phase, cells undergo a number of changes in both intracellular biochemistry and DNA topology (Siegele \& Kotler, 1992). Their overall metabolic rates decrease to a very low level but the ability to transport substrates into the cell is unaffected. Entry of aldehyde and oxygen is therefore not a limiting factor. It has been previously suggested that Gram-positive cells have inadequate capacity to regenerate reduced flavin mononucleotide, which is an essential substrate of the luminescent reaction (Karp, 1989), and this may be more apparent during stationary phase. Equally, it may be that stationary-phase shut-off is a natural property of the lac promoters.

Both the $l a c R$ and $l a c$ operon promoters were induced during growth on lactose; approximately sevenfold and fivefold respectively. Expression of both promoters was repressed during growth on glucose. These data suggest that the $l a c R$ repressor acts as a negative regulator of the lactose operon during growth on glucose and that it also autoregulates itself. The $l a c R$ promoter proved to be a very efficient lactococcal promoter, being at least four times stronger than the lac operon promoter. It was also induced to a greater extent than the lac operon promoter during growth on lactose. A model of negative regulation of the lac operon promoter by the lacR repressor has been proposed (Van Rooijen \& De Vos, 1990) and this is confirmed by the luciferase data presented here. Van Rooijen \& De Vos (1990) used Northern blot analyses to show the presence of a $1.2 \mathrm{~kb}$ lac $R$ transcript whose synthesis was apparently repressed fivefold during growth on lactose, indicating activation of the lac $R$ gene during growth on glucose. However, the luciferase data presented here clearly demonstrate that the lacR promoter was repressed by growth on glucose, implying that $l a c R$ acts to repress transcription initiated from the promoters of both the lac operon and the lacR gene. Varying the level of repressor in response to lactose availability could provide a fine control of gene expression. The elevated level of repressor during induction would not reduce transcription of the lac operon as the repressor would be inactive in the presence of the inducer. Increased amounts of inactive repressor during induction could however serve to effect more rapid repression of transcription once a cell exhausts its supply of lactose. As the amount of inducer decreases, active repressor molecules would be formed more rapidly and in the continued absence of inducer a reduced level of repressor would maintain repression of the lactose operon. A cell with a repressed lactose operon that encountered lactose would require less inducer to be formed before full induction of the operon took place. An analogous explanation for the autoregulation of the repressor in fine-tuning gene regulation has been proposed for the $E$. coli tryptophan operon (Yanofsky \& Crawford, 1987).

The luminescence data show that the transcription terminator downstream of lacR reduces transcription by a factor of 20 . Previous studies using $\beta$-galactosidase as the reporter gene indicated a fivefold reduction (Van Rooijen et al., 1992), perhaps illustrating the superior sensitivity of the lux assay.

MG1363 cells lack the lac operon genes and are therefore unable to ferment lactose via the PEP-PTS 
pathway. Although there is evidence for the presence of a lactose permease gene (De Vos \& Simons, 1988; Kim \& Batt, 1988), MG1363 appears to have no $\beta$ galactosidase activity and internalized lactose cannot be metabolized. Despite this, slow growth $(71 \%$ of the growth rate on glucose) does occur on LM17 medium, which contains lactose as the only added sugar, presumably due to the presence of other metabolizable components in M17 medium. As expected, luminescence levels of plasmid-carrying MG1363 cells grown on LM17 are much lower than those of the equivalent MG5267 strains. For MG1363 cells transformed with pFI400, pFI402 and pFI517 and grown in glucose, transcription of both the lacR gene and the lac operon will occur. The $l a c R$ repressor will associate with the operator sites (Van Rooijen et al., 1992), permitting only the repressed levels of transcription. The in vitro inducer of the lactose operon is tagatose 6-phosphate (W. M. De Vos, personal communication), which should not be produced by the lactose-negative MG1363 strain; hence no induction of the operon is expected. The levels of lux gene expression might therefore be expected to be similar for MG5267 and MG1363 strains grown on glucose. Whilst this was true for strains carrying pFI400 or pFI517 significantly greater expression of $l u x$ was found for MG5267 carrying pFI402 compared to MG1363 carrying the same plasmid. Analogous experiments utilizing the $\beta$-galactosidase gene as the reporter gene produce the same results (Griffin \& Gasson, 1993). This difference appears to be specific for expression from the lac operon promoter, and the presence of chromosomal lactose genes in this case appeared to elevate lac operon expression even though no lactose was present in the growth medium. Background expression of one or more chromosomal lactose genes in MG5267 could generate low levels of a metabolite with inducer activity, causing higher levels of expression due to partial induction of the lac operon. Alternatively, the lac $X$ gene, which has yet to be assigned a function, may act as a positive regulator in MG5267.

In order to investigate the role of the lacR repressor further, plasmids pFI530 and pFI518 were constructed. Transformation of MG5267 with these plasmids proved difficult and only unstable transformants carrying pFI530 were recovered. In MG5267 strains harbouring these plasmids, only one copy of the lacR gene would be present compared to the multiple copies of the lac operator regions (Van Rooijen et al., 1992). Although some repression of the $l a c$ operon and lacR gene would occur during growth on glucose the repressor molecules are effectively titrated out. An increased level of transcription would be expected compared to the MG5267 strains carrying pFI400, pFI402 and pFI517, which contain an equivalent number of repressor molecules and operator regions. Attempts to transform
pFI518 and pFI530 into L. lactis MG1363 also proved unsuccessful. In MG1363 the lactose promoter on these plasmids will be expressed in the absence of lacR and they are therefore not subject to repression whether grown in GM17 or LM17. In these circumstances it is possible that excessive transcription of the lux genes could occur, resulting in host cell lethality, or structural instability of the plasmids. Another possible explanation may be the occurrence of a 'dark' reaction associated with the luciferase which takes place in the absence of aldehyde and produces $\mathrm{H}_{2} \mathrm{O}_{2}$ (Hastings \& Nealson, 1977). At high levels of $\operatorname{lu} x A B$ expression this could be lethal.

Luminescence assays were also performed on cultures grown in a mixture of glucose and lactose (Fig. 3). Intermediate levels of luminescence between the high values for lactose and the lower levels for glucose were obtained, supporting the possibility of catabolite repression of the L. lactis lac operon (De Vos \& Simons, 1988). Strains of Lactococcus have been shown to have intermediate levels of phospho- $\beta$-galactosidase activities under the same conditions (J. Smart, personal communication).

Whilst further work is required to fully determine the regulation of lac operon expression, this work demonstrates that the lactose promoters can be used to generate a range of promoter efficiencies coupled to regulation by carbon source. This provides a valuable approach to the more precise control of gene expression levels which should find application in the control of both heterologous and homologous genes in lactococci. Also the luciferase assay has clearly been shown to have considerable potential as a reporter for fine analyses of gene expression in lactococci.

This research was supported by contract BIOT CT-910263 from the BRIDGE programme of the European Community. Plasmid pSB262 was kindly donated by Dr S. Park. We are grateful to Dr R. LePage and Dr J. Wells of Cambridge University for valuable discussions.

\section{References}

Ahmad, K. A. \& Stewart, G. S. A. B. (1991). The production of bioluminescent lactic acid bacteria suitable for the rapid assessment of starter culture activity in milk. Journal of Applied Microbiology 70, 525-557.

Birnboim, H. C. \& Doly, J. (1979). A rapid alkaline extraction procedure for screening recombinant plasmid DNA. Nucleic Acids Research 7, 1513-1519.

BLISSET, D. L. \& ANDERSON, R. L. (1973). Lactose and D-galactose metabolism in Staphylococcus aureus: pathway of D-galactose-6phosphate degradation. Biochemical and Biophysical Research Communications 52, 641-647.

Boylan, M. O., Pelletier, J., Dhepagnon, S., Trudel, S., Sonenberg, N. \& Meighen, E. A. (1989a). Construction of a fused $l u x A B$ gene by site-directed mutagenesis. Journal of Bioluminescence and Chemiluminescence 4, 310-316.

Boylan, M., Pelletier, J. \& Meighen, E. A. (1989 $b$ ). Fused bacterial luciferase subunits catalyse light emission in eukaryotes and prokaryotes. Journal of Biological Chemistry 646, 1915-1918. 
Carmi, O. A., Stewart, G. S. A. B., Ulitzur, S. \& Kuhn, J. (1987). Use of bacterial luciferase to establish a promoter probe vehicle capable of non-destructive real-time analysis of gene expression in Bacillus spp. Journal of Applied Bacteriology 169, 2165-2170.

Casadaban, M. J. \& CoHEN, S. N. (1980). Analysis of gene control signals by DNA fusion and cloning in Escherichia coli. Journal of Molecular Biology 138, 179-207.

David, S., Van Der Rest, M., Driessen, A. M. J., Simons, G. \& De Vos, W. M. (1990). Nucleotide sequence and expression in Escherichia coli of the Lactococcus lactis citrate permease gene. Journal of Bacteriology 172, 5789-5794.

DE Vos, W. M. \& GASSON, M. J. (1989). Structure and expression of the Lactococcus lactis gene for phospho- $\beta$-galactosidase (lacG) in Escherichia coli and Lactococcus lactis. Journal of General Microbiology 135, 1833-1846.

DE Vos, W. M. \& Simons, G. (1988). Molecular cloning of lactose genes in dairy streptococci: the phospho- $\beta$-galactosidase and $\beta$ galactosidase genes and their expression products. Biochemie 70, 461-473.

De Vos, W. M., Boerrigter, I., Van Rooijen, R. J., Rfiche, B. \& Hengstenderg, W. (1990). Characterisation of the lactose-specific enzymes of the phosphotransferase system in Lactococcus lactis. Journal of Biological Chemistry 265, 22554-22560.

Escher, A., O'Kane, D. J., Lee, D. J. \& Szalay, A. A. (1989). Bacterial luciferase $\alpha \beta$ fusion protein is fully active as a monomer and highly sensitive in vivo to elevated temperature. Proceedings of the National Academy of Sciences of the United States of America 86, 6528-6532.

Friedland, J. \& Hastings, J. W. (1967). The reversibility of denaturation of bacterial luciferases. Biochemistry 6, 2893-2900.

Gasson, M. J. (1983). Plasmid complements of Streptococcus lactis NCDO712 and other lactic streptococci after protoplast induced curing. Journal of Bacteriology 154, 1-9.

Griffin, H. G. \& Gasson, M. G. (1993). The regulation of expression of the Lactococcus lactis lactose operon. Letters in Applied Bacteriology (in the Press).

Guijarro, J., Santamaria, R., Schauer, A. \& Losick, R. (1988). Promoter determining the timing and spatial localization of transcription of a cloned Streptomyces coelicolor gene encoding a spore associated polypeptide. Journal of Bacteriology 170, 1895-1901.

Hastings, J. W. \& Nealson, K. H. (1977). Bacterial bioluminescence. Annual Review of Microbiology 31, 549-595.

Holo, H. \& Nes, I. F. (1989). High frequency transformation, by electroporation, of Lactococcus lactis subsp. cremoris grown with glycine in osmotically stabilized media. Applied and Environmental Biology 55, 3119-3123.

Jacobs, M., Hill, P. J. \& Stewart, G. S. A. B. (1991). Highly bioluminescent Bacillus subtilis obtained through high-level expression of a luxAB fusion gene. Molecular and General Genetics 220, 251-256.

KARP, M. (1989). Expression of bacterial luciferase genes from Vibrio harveyi in Bacillus subtilis and Escherichia coli. Biochimica et Biophysica Acta 1007, 84-90.

KIM, S. G. \& BATT, C. A. (1988). Heterologous expression and stability of the Escherichia coli $\beta$-galactosidase gene in Streptococcus lactis by translation fusion. Food Microbiology 5, 59-73.

Kirchner, G., Roberts, J. L., Gustafason, G. D. \& Ingolia, T. D. (1989). Active bacterial luciferase from a fused gene: expression of a Vibrio harveyi lux $A B$ translational fusion in bacteria, yeast and plant cells. Gene 81, 349-354.

KoK, J., Hill, D., HaAndrikman, A. J., De Reuver, M. J. B., LaAn, H. \& VeNEMA, G. (1988). Deletion analysis of the proteinase gene of Streptococcus cremoris Wg2. Applied and Environmental Microbiology 54, 239-244.

LENNOX, E. S. (1955). Transduction of linked genetic characters of the host bacteriophage P1. Virology 1, 190-200.

Maniatis, T., Fritsch, E. F. \& SAmbrooK, J. (1982). Molecular Cloning: a Laboratory Manual. Cold Spring Harbor, NY: Cold Spring Harbor Laboratory.
MeIGHEN, E. A. (1988). Enzymes and genes from the lux operons of the bioluminescent bacteria. Annual Review of Microbiology 42, 151-176.

Meighen, E. A. (1991). Molecular biology of bacterial bioluminescence. Microbiological Reviews 55, 123-142.

Olsson, O., Escher, A., Sandberg, G., Schell, J., Koncz, C. \& SzAlay, A.A. (1989). Engineering of monomeric bacterial luciferases by fusion of $l u x A$ and $l u x B$ genes in Vibrio harveyi. Gene 81, 335-347.

Park, S. F., Stewart, G. S. A. B. \& Kroll, R. G. (1992). The use of bacterial luciferase for monitoring the environmental regulation of expression of genes encoding virulence factors in Listeria monocytogenes. Journal of General Microbiology 138, 2619-2627.

Sakharov, G. N., Ismailov, A. D. \& Danilov, V. S. (1988). Temperature dependences of the reaction of bacterial luciferases from Beneckea harveyi and Photobacterium fischeri. Biochemistry (USSR) 53, 770-776.

Schauer, A., Ranes, M., Santamaria, R., Guijarro, J., Lawlor, E., Mondez, C., Chater, K. \& Losick, R. (1988). Visualizing gene expression in time and space in the filamentous bacterium Streptomyces coelicolor. Science 240, 768-772.

ShINE, J. \& Dalgarno, L. (1974). The $3^{\prime}$ terminal sequence of Escherichia coli $16 \mathrm{~S}$ ribosomal RNA: complementarity to nonsense triplets and ribosome binding sites. Proceedings of the National Academy of Sciences of the United States of America 71, 1342-1346.

Siegele, D. A. \& KotleR, R. (1992). Life after log. Journal of Bacteriology 174, 345-348.

Simons, G., Buys, H., Hogers, R., Koenhen, E. \& De Vos, W. M. (1990). Construction of a promoter-probe vector for lactic acid bacteria using the lacG gene of Lactococcus lactis. Developments in Industrial Microbiology 31, 31-39.

SoHASKeY, C. D., IM, H. \& SchaueR, A. T. (1992). Construction and application of plasmid and transposon based promoter probe vectors for Streptomyces spp. that employ a Vibrio harveyi luciferase reporter cassette. Journal of Bacteriology 174, 367-376.

Stewart, G. S. A. B. \& Williams, P. (1992). lux genes and the application of bacterial bioluminescence. Journal of General Microbiology 138, 1289-3000.

SZITTNER, R. \& MEIGHEN, E. (1990). Nucleotide sequence, expression and properties of luciferase coded by lux genes from a terrestrial bacterium. Journal of Biological Chemistry 256, 16581-16587.

TerzaGHI, B. E. \& Sandine, W. E. (1975). Improved medium for lactic streptococci and their bacteriophages. Applied Microbiology 29, $807-813$.

VerhuE, W. M. \& TJan, F. S. B. (1991). Study of the citrate metabolism of Lactococcus lactis subsp. lactis biovar diacetylactis by means of ${ }^{14} \mathrm{C}$ nuclear magnetic resonance. Applied and Environmental Microbiology 11, 3371-3377.

Van Rooijen, R. J. \& De Vos, W. M. (1990). Molecular cloning, transcriptional analysis and nucleotide sequence of $l a c R$, a gene encoding the repressor protein of the phosphotransferase system of Lactococcus lactis. Journal of Biological Chemistry 265, 18499-18503.

Van Rooijen, R. J., Van ScalkwiJk, S. \& De Vos, W. M. (1991). Molecular cloning, characterization, and nucleotide sequence of the tagatose-6-phosphate pathway gene cluster of the lactose operon of Lactococcus lactis. Journal of Biological Chemistry 266, 7176-7181.

Van Rooljen, R. J., Gasson, M. J. \& DE Vos, W. M. (1992). Characterization of the lactose operon promoter: contribution of flanking sequences and lacR repressor to promoter activity. Journal of Bacteriology 174, 2273-2280.

Vos, P., Simons, G., Siezen, R. J. \& De Vos, W. M. (1989). Primary structure and organization of the gene for a prokaryotic, cellenvelope located serine proteinase. Journal of Biological Chemistry 264, 13579-23585.

YANOFSKY, C. \& CRAWFoRd, I. P. (1987). The tryptophan operon. In Escherichia coli and Salmonella typhimurium, Cellular and Molecular Biology, pp. 1453-1472. Edited by J. L. Ingraham, K. B. Low, B. Magasanik, M. Schaechter \& H. E. Umbarger. Washington, DC: American Society for Microbiology.

Yanisch-Perron, C., VieIRA, J. \& Messing, J. (1985). Improved M13 phage cloning vectors and host strains: nucleotide sequences of the M13mp18 and pUC19 vectors. Gene 33, 103-119. 